D.C. Oxorn MD FRCP(C),

D.C. Chung MD FRCP(C), A.M. Lam MD FRCP(C)

\title{
Continuous in-vivo monitoring of arterial oxygen tension in a patient treated with bleomycin
}

Patients receiving bleomycin therapy may develop pulmonary fibrosis. The risk of fibrosis is increased by the administration of general anaesthesia and fatal cases with pulmonary lesions resembling those of "oxygen toxicity" have been reported. The causes are not entirely clear but the enriched inspired oxygen given intraoperatively or postoperatively has been identified as an etiological factor. Optimal intraoperative management thus requires the administration of the lowest inspired oxygen fraction $\left(\mathrm{F}_{1} \mathrm{O}_{3}\right)$ compatible with adequate oxygenation. To achieve this aim safely, continuous in vivo monitoring of arterial oxygen tension would be preferable to intermittent sampling of blood gases. We report the successful management of a patient undergoing thoracotomy following bleomycin therapy using an intravascular $\mathrm{PO}_{2}$ sensor to monitor arterial oxygen tension continuously. The uses and limitations of the $\mathrm{PO}_{2}$ sensor are discussed.

\section{Key words}

EQUIPMENT: arterial catheter; HYPOXIA, MEASUREMENT TECHNIQUES: oxygen electrode; TOXICITY: oxygen; BLEOMYCIN: anaesthetic management.
From the Department of Anaesthesia, University Hospital and University of Western Ontario, London, Ontario. Address correspondence to: Dr. A.M. Lam, Department of Anaesthesia, Lniversity Hospital, P.O. Box 5339, Postal Stn. A, London, Canada N6A 5A5.
Bleomycin has been used in the preparation of patients with dysgenetic testicular neoplasms ${ }^{1}$ and epidermoid oesophageal carcinomas ${ }^{2}$ before surgery. Pulmonary fibrosis is seen in five to 40 per cent of patients treated with bleomycin, and is a major cause of morbidity and mortality. This complication has been especially noted in the elderly, in those treated with large doses of the drug, in those receiving thoracic radiotherapy, and more recently, in patients receiving increased inspired concentrations of oxygen. ${ }^{1-5}$ Goldiner reported the incidence of fatal pulmonary fibrosis in a group of patients treated with bleomycin and found that the mean inspired oxygen fraction $\left(\mathrm{F}_{1} \mathrm{O}_{2}\right)$ of the survivor group was 0.24 while that of the nonsurvivor group was $0.39 .^{1}$ The arterial oxygenation was monitored by intermittent sampling of blood gases. He concluded that the risk of fatal pulmonary fibrosis can be reduced by decreasing the inspired oxygen concentration intraoperatively as well as postoperatively. Allen ${ }^{4}$ reported two thoracotomies in a patient receiving bleomycin who received an $\mathrm{FIO}_{2}$ of $0.21-0.25$ intraoperatively. During some unexpected bleeding, the $\mathrm{FIO}_{2}$ was not increased, and an arterial blood gas revealed an arterial oxygen tension of $45 \mathrm{mmHg}$. The authors "felt obliged to maintain the $\mathrm{FIO}_{2}$ within known safe limits, and were forced to accept the degree of hypoxia produced by one lung anaesthesia." This case report illustrates a clinical setting not uncommonly encountered. Patients treated with tleomycin frequently present for thoracotomy and one lung anaesthesia, either for oesophageal resection or for removal of a malignant tumour. The risk of pulmonary fibrosis must be balanced against the hazards 
of hypoxaemia during one lung anaesthesia. The goal is to deliver the lowest $\mathrm{FrO}_{2}$ possible, while avoiding the development of hypoxaemia. Intermittent determination of bload gases as a monitor of oxygenation is plagued by a long lag time between sampling and feedback. We describe the successful intraoperative management of a patient undergoing thoracotomy who was predisposed to the development of pulmonary fibrosis by recent treatment with high doses of bleomycin. We monitored continuously his arterial oxygen tension using an intravascular $\mathrm{PO}_{2}$ sensor with a Clark-type electrode (Roche, part no. 8803406 , supplied by Kontron) and adjusted the $\mathrm{FIO}_{2}$ accordingly.

\section{Case report}

A twenty-four-year-old male presented with a two-week history of cough, pleuritic chest pain, and a twenty-pound weight loss over the preceding three months. On physical examination, there was tracheal deviation to the right, and breath sounds were diminished over the left hemithorax. A chest $x$-ray revealed a mediastinal mass extending into the left lower lobe; the right lung was normal. Computerized tomography showed an anterior mediastinal mass with compression of the left main stem bronchus and areas of patchy atelectasis in the left lung. Biopsy revealed an embryonal cell carcinoma.

The patient was started on a regimen consisting of vinblastine, cisplatinum, and bleomycin which lasted 12 weeks. The total dose of bleomycin was 228 units $/ \mathrm{m}^{2}$ body surface area. No radiotherapy was given. Six days aftcr the end of his bleomycin treatment, the patient was re-admitted for increasing cough and shortness of breath. A chest $x$-ray showed no change from the pretreatment films. Because of the increasing severity of symptoms, the decision was made to perform a left thoracotomy to remove the tumour mass and possibly perform a left pneumonectomy.

Preoperative pulmonary function studies revealed mild hypoxacmia and a marked restrictive defect (Table I), attributed to atelectasis in the left lung. Haemoglobin was $104 \mathrm{gm} /$; serum electrolytes, blood urea nitrogen, creatinine and urinalysis were all within normal limits.

Eight days after the last dose of bleomycin the patient was taken to the operating room. He was premedicated with $15 \mathrm{mg}$ diazepam by mouth two
TABLE I

\begin{tabular}{|c|c|c|}
\hline \multicolumn{3}{|c|}{ Freoperative blood gases } \\
\hline $\mathrm{PaO}_{2}$ & $\begin{array}{l}(\mathrm{kPa}) \\
(\mathrm{mmHg})\end{array}$ & $\begin{array}{l}10 \\
75\end{array}$ \\
\hline $\mathrm{PaCO}_{2}$ & $\begin{array}{l}(\mathrm{kPa}) \\
(\mathrm{mmHg})\end{array}$ & $\begin{array}{c}5.1 \\
38\end{array}$ \\
\hline $\mathrm{pH}$ & & 7.44 \\
\hline $\mathrm{HCO}_{3}^{-}$ & $(\mathrm{mmol} / \mathrm{L})$ & 25 \\
\hline $\mathrm{BE}^{-}$ & & 0.94 \\
\hline $\mathrm{FrO}_{2}$ & & 0.21 \\
\hline \multicolumn{3}{|c|}{ Preoperative pulmonary functions tests } \\
\hline & Predicted & Observed \\
\hline FRC (L) & 3.02 & 1.18 \\
\hline RV (L) & 1.31 & 0.59 \\
\hline TLC (L) & 5.50 & 2.21 \\
\hline $\mathrm{FEV}_{1}(\mathrm{~L})$ & 3.18 & 1.25 \\
\hline FVC (L) & 3.8 & 1.58 \\
\hline \multicolumn{3}{|c|}{ DLCO corrected } \\
\hline for $\mathrm{Hgb}$ & 27.50 & 14.31 \\
\hline
\end{tabular}

hours preoperatively and anaesthesia was induced with sodium thiopental and succinylcholine. He was then intubated with a cuffed, single lumen $8.5 \mathrm{~mm}$ orotracheal tube and anaesthesia was maintained with oxygen, nitrogen, morphine, pancuronium and enfurane at an inspired concentration of one to two per cent. Body temperature was maintained using a thermal blanket and the nasopharyngeal temperature never feli below $36.8^{\circ} \mathrm{C}$. Central venous pressure was monitored with an internal jugular venous catheter, and maintained between 8-12 mmHg. The right radial artery was cannulated with an 18 gauge $1 \frac{1}{2}$ inch catheter (Jelco) for the continuous monitoring of systemic pressure. Inspired oxygen concentration was monitored continuously with a fuel-cell oxygen analyzer (Biomarine). Using an aseptic technique, the intravascular $\mathrm{PO}_{2}$ sensor, with the electrode mounted at the end of the $35-\mathrm{cm}$ filament, was inserted through the arterial catheter and a special stopcock which allowed simultaneous pressure monitoring (Figure 1). To maintain the patency of the cannula and to prevent the collection of platelet thrombi on the electrode, a continuous flushing device (Accuflush MX530-Y, Medex Inc.) with a flow rate of $30 \mathrm{ml} / \mathrm{hr}$ was used. In addition, intermittent manual flushing with a $6 \mathrm{ml}$ syringe was performed. The intravascular $\mathrm{PO}_{2}$ was calibrated with in vitro analysis 


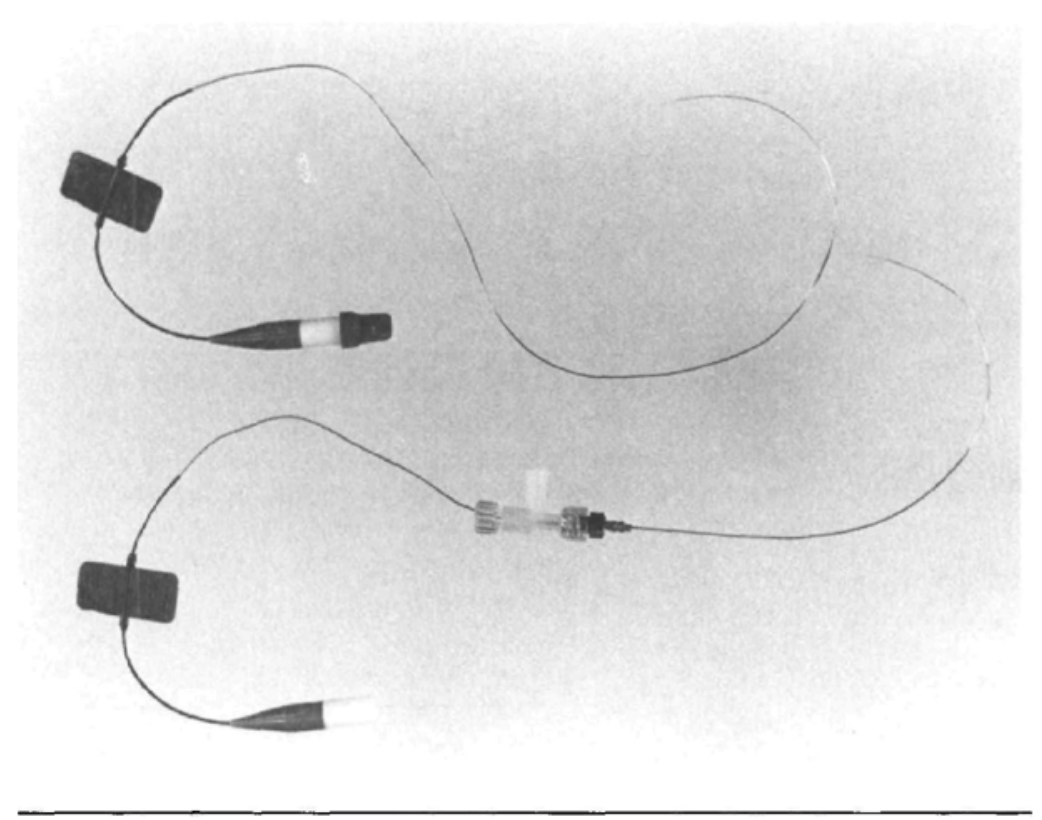

FIGURE 1 Top, the intravascular $\mathrm{PO}_{2}$ sensor alone, Bottom, the sensor fitted through the stopcock and the Jelco intravenous catheter. The electrode is located at the distal portion of the scrsor.

(Radiometer BMS 3 MK 2) of an arterial blood sample at the beginning of the procedure. In addition to the continuous monitoring of the intravascular $\mathrm{PO}_{2}\left(\mathrm{PlvO}_{2}\right)$, intermittent samples were taken for blood gas analysis (Table II). All blood samples were capped, placed on ice and analyzed within an hour. Tumour removal and left pneumonectomy were performed and the procedure lasted six hours. Estimated blood loss was $3000 \mathrm{ml}$ and was replaced with warmed bank blood and crystalloid.

The results of the five sets of blood gas determinations and the corresponding $\mathrm{PIVO}_{2}$ readings are shown in Table II. After the initial calibration (set 1), the $\mathrm{PIVO}_{2}$ reading closely approximated the in vitra arterial oxygen tension $\left(\mathrm{PaO}_{2}\right)$. Set 2 was taken after the chest wall had been opened. Set 3 was taken when the left pulmonary artery was clamped because of uncontrolled bleeding, after which the $\mathrm{FIO}_{2}$ was increased to 0.4 . The left main stem bronchus was clamped forty minutes later. Set 4 was then taken revealing an increase in $\mathrm{PaO}_{2}$ and
$\mathrm{PivO}_{2} . \mathrm{FIO}_{2}$ was immediately decreased to 0.23 , leading to a decrease in $\mathrm{PaO}_{2}$ and $\mathrm{PIVO}_{2}$ (set 5). The apparent discrepancy between intravascular and arterial $\mathrm{PO}_{2}$ in sample 4 was caused by the transient disequilibrim as the $\mathrm{FIO}_{2}$ was decreased, the response time of the intravascular $\mathrm{FO}_{2}$ electrode being approximately 90 seconds. Throughout the procedure, $\mathrm{FrO}_{2}$ concentration was adjusted to maintain the $\mathrm{PrvO}_{2}$ between 60 and $70 \mathrm{mmHg}$, a range considered to be acceptable, to minimize the risk of pulmonary fibrosis.

Neuromuscular blockade was fully reversed at the end of the procedure, and the patient was extubated in the operating room. The radial arterial catheter and $\mathrm{PO}_{2}$ sensor were removed. The patient was allowed to breathe a mixture of oxygen and nitrogen with a $\mathrm{FIO}_{2}$ of 0.25 for one hour and then room air. Recovery in the intensive care unit was uneventful, and postoperative blood gas results did not differ from preoperative values. Follow-up chest $x$-rays at one month, two months and six months showed no evidence of right lung damage. 
TABLE II Blood gas results

\begin{tabular}{|c|c|c|c|c|c|c|c|c|c|}
\hline \multirow[b]{2}{*}{ Sample } & \multirow[b]{2}{*}{$\mathrm{FlO}_{2}$} & \multicolumn{2}{|c|}{$\mathrm{PIVO}_{2}$} & \multicolumn{2}{|l|}{$\mathrm{PaO}_{2}$} & \multicolumn{2}{|c|}{$\mathrm{PaCO}_{2}$} & \multirow[b]{2}{*}{$p H$} & \multirow{2}{*}{$\begin{array}{l}\text { Saturation } \\
(\%)\end{array}$} \\
\hline & & $k P a$ & $m m H g$ & $k P u$ & $m m H g$ & $k P a$ & $m m H g$ & & \\
\hline 1 & 0.25 & 8.8 & 66 & 10.9 & 82 & 6.5 & 49 & 7.31 & 95 \\
\hline 2 & 0.24 & 8.9 & 67 & 10.4 & 78 & 6.3 & 47 & 7.35 & 95 \\
\hline 3 & 0.21 & 5.9 & 44 & 6.4 & 48 & 7.3 & 55 & 7.30 & 80 \\
\hline 4 & 0.40 & 20.1 & 151 & 17.3 & 130 & 7.1 & 53 & 7.31 & 98 \\
\hline 5 & 0.23 & 9.7 & 73 & 9.2 & 69 & 5.7 & 43 & 7.39 & 93 \\
\hline
\end{tabular}

See text for details of sampling times.

\section{Discussion}

Bleomycin may exert its cytotoxic effect by fragmentation of DNA molecules through chelation of ferrous ions. ${ }^{6}$ The mechanism by which it causes pulmonary fibrosis is unknown. In patients treated with bleomycin, moderately enriched levels of inspired oxygen may cause pulmonary toxicity at concentrations ordinarily considered benign. While neither the threshold oxygen concentration capable of causing this complication, nor the safe preoperative bleomycin-free interval is known, these two factors probably have a synergistic influence. Thus, in LaMantia's retrospective analysis of bleomycin and anaesthesia, he found that a mean $\mathrm{FIO}_{2}$ of 0.38 did not result in postoperative pulmonary complications in eleven patients. ${ }^{7}$ However, the mean interval between bleomycin and surgery was eleven months, considerably greater than what was reported in the series of Goldiner and Nygaard where increased pulmonary morbidity was found. ${ }^{1,2}$

Our patient was at high risk of developing pulmonary fibrosis for several reasons. As the sensitization effect of bleomycin is inversely related to the duration of the bleomycin free-interval, ${ }^{8}$ a short interval implies an increased risk of pulmonary fibrosis, and in our patient, the course of bleomycin was completed just eight days prior to surgery. Most other reports of pulmonary complications described bleomycin-free intervals of four to twelve months. ${ }^{1.2 .7}$ Preoperative pulmonary function was abnormal as demonstrated by the pulmonary function tests. In addition, the surgical procedure (thoracotomy and pneumonectomy) is associated with the potential of causing hypoxaemia, thus necessitating an enriched inspired oxygen concentration, possibly higher than what may be required in order to allow a margin of safety. Optimal anaesthetic management, therefore, is to maintain minimal inspired oxygen concentration compatible with adequate arterial oxygenation. The intermittent sampling of blood gases is not entirely satisfactory because of the inherent time delay between sampling and reporting of results. Inadvertent exposure to a dangerously low arterial oxygen level may therefore result. We successfully achieved our aim by monitoring the arterial oxygen tension in vivo continuously using an intravascular $\mathrm{PO}_{2}$ sensor. Good correlation with in vitro determination of arterial blood gases have been reported with critically ill patients ${ }^{9}$ managed in an intensive care unit as well as during hypotensive anaesthesia. ${ }^{10}$ The intravascular $\mathrm{PO}_{2}$ sensor utilizes a Clark-type electrode incorporated at the end of the $35 \mathrm{~cm}$ sensor and its performance is not significantly influenced by the use of nitrous oxide and other anaesthetic gases. Halothane, however, can interact electrochemically with the electrode and render the readings spuriously high. " Accordingly halothane was not used in the anaesthetic management. The use of the intra-arterial $\mathrm{PO}_{2}$ sensor for continuous monitoring of $\mathrm{PaO}_{2}$ necessitates arterial cannulation. However, intra-arterial pressure monitoring is often indicated in the management of ill patients undergoing anaesthesia and surgery. Using an 18 gauge catheter, and a special stopcock, the ability to monitor blood pressure and to perform intermittent blood sampling is retained while the in vivo $\mathrm{PaO}_{2}$ is measured continuously. Deposition of platelet thrombi on the electrode can cause underreading and care must be taken to prevent it. Insertion of a larger cannula (for example 16 gauge) would circumvent this problem, but would increase 
the risk of subsequent arterial thrombosis or haemorthage. We chose to use a smaller catheter and rely on a high flow continuous flush device and intermittent manual flushing.

In patients catheterized for twenty-four hours or more, the risk of subsequent radial arterial occlusion is higher with an 18-gauge catheter compared to a 20 -gauge catheter, ${ }^{12}$ but no comparable study has been done in cases with a shorter catheterization period. Moreover, a previously reported series of patients managed in a similar manner during hypotensive anaesthesia had no complications. ${ }^{10}$ Thus, the risk of using an 18-gauge catheter was deemed justified considering the potential benefits.

Other possible monitors of oxygenation include monitoring of mixed venous oxygen saturation, transcutaneous oxygen tension and ear oximetry. Although the technology of continuous monitoring of mixed venous oxygen saturation $\left(\mathrm{SvO}_{2}\right)$ is available, ${ }^{13}$ we do not feel it satisfies our aim. $\mathrm{SvO}_{2}$ is determined not only by arterial oxygenation and oxygen consumption, but also by the cardiac output. In the face of a normal $\mathrm{PaO}_{2}$, an adequate $\mathrm{SvO}_{2}$ is a satisfactory and reassuring monitor of oxygen delivery. However, if used alone, a normal $\mathrm{SvO}_{2}$ may be associated with either an undesirably low or an unacceptably high $\mathrm{PaO}_{2}$; therefore, it is difficult and dangerous to adjust the $\mathrm{FIO}_{2}$ to maintain a minimum $\mathrm{SvO}_{2}$. Transcutaneous oxygen tension is dependent on the skin blood flow and local metabolism and has not been found to be reliable for monitoring the adult surgical patient during anaesthesia ${ }^{14}$ Ear oximetry has been proved to be accurate under experimental conditions, ${ }^{14}$ and is a plausible alternative, but it is difficult to maintain the ear piece in the correct position during a long procedure and the surgical draping further compounds the problem. Moreover, it suffers the similar drawback as monitoring of mixed venous oxygen saturation; because of the nature of the oxygen-haemoglobin dissociation curve, it is easy to increase the $\mathrm{FiO}_{2}$ to maintain a satisfactory saturation, but it is difficult to adjust the $\mathrm{FIO}_{2}$ to maintain a minimum oximetry reading. However, it would seem ideal to monitor both arterial oxygen tension and saturation continuously.

In conclusion, we have described the continuous, in vivo monitoring of arterial oxygen tension using an intravascular $\mathrm{PO}_{2}$ sensor as a useful adjunct in the successful management of a bleomycin-treated patient undergoing thoracotomy and pneumonectomy. The use of this sensor would also seem to be appropriate in other situations where sudden development of hypoxaemia can occur, for example, during one lung anaesthesia or when managing a patient with rapidly deteriorating pulmonary disease.

\section{References}

1 Goldiner PL, Carlon GC, Cvitkovic E, Schweizer O, Howland WS. Factors influencing postoperative morbidity and mortality in patients treated with bleomycin. Br Med J 1978; 1: 1664-7.

2 Nygaard K, Smith-Erichsen N, Hatlevoll $R$, et al. Pulmonary complications after bleomycin, irradiation, and surgery for esophageal cancer. Cancer 1978; 41: 17-22.

3 Douglas MJ, Coppin CML. Bleomycin and subsequent anaesthesia. A retrospective study at Vancouver General Hospital. Can Anaesth Soe J 1980; 27: 449-52.

4 Allen SC, Riddell GS, Butchart EG. Bleomycin therapy and anaesthesia. Anesthesia 1981; 36: 60-3.

5 Goldiner PL, Schweizer $O$. The hazards of anaesthesia and surgery in bleomycin treared patients. Seminars in Oncology 1979; 6: 121-.4

6 Lown JW. Sim SK. The mechanism of the bleomycir-induced cleavage of DNA. Biochemical and Biophysical Research Communications. 1977; 4: 1150-7.

7 LaMantia KR, Glick JH, Marshall EIE. Use of oxygen enriched gas mixtures during anaesthesia for patients treated with bleomycin. Anesthesiology 1982; 57: A484.

8 Tryka AF, Godleski JJ, Skornik WA. Brain JD. Bleomycin and $70 \%$ oxygen exposure, early and late effects. Am Rev Respir Dis 1982; 125 : 92.

9 Rithalia SVS, Bennett PJ, Tinker J. The performance characteristics of an intra-irterial oxygen electrode. Intensive Care Med 1981; 7: 305-7.

10 Kieraszewicz HT, Lam AM. Continuous monitoring of oxygenation during hypotensive anaesthesia evaluation of an intravascular $\mathrm{PO}_{2}$ electrode. Can Anaesth Soc J 1983; 30: \$62.

11 Eberhard $P$. Fehlmann W, Mindi W. An electrochemical sensor for continuous intravascular oxygen 
monitoring. Biotelemetry Patient Monitoring 1979; 6: 16-31.

12 Bedford $R F$. Radial arterial function following percutaneous cannulation with 18-and 20-gauge catheters. Anesthesiology 1977; 47: 37-9.

13 Allison J, Dodds, WA, Jenkins LC, Turnbull $\mathrm{KW}$, Tyers GFO, Walmsley $B$. Continuous mixed venous oxygen saturation in adults with cardiovascular disease. Abstracts, Can Anaesth Soc Meeting, 1981; A-2.

14 Knill RL, Clement JL, Kieraszewicz HK, Dodgson $B G$. An asscssment of two non-invasivc monitors of arterial oxygenation in anesthetized man. Anesth Analg 1982; 61: 582-6.
Résumé

Les patients soumis à une thérapie d̀ la blémycine peuvent développer une fibrose pulmonaire. Le risque est accentué par l'anesthésie gènérale et des cas mortels avec lésions pulmonaires ressemblant à celles de la toxicité à l'oxygène ont été rapportés. L'étiologie n'est pas encore entièremenl clarifiée mais l'administration d'oxygène supplémentaire dans la période péri-opéraroire a été incriminée comme facteur étiologique. La meilleure conduite per-opératoire est donc l'administration de la plus petite concentration d"oxygène $\left(\mathrm{F}_{2} \mathrm{O}_{2}\right)$ compatible avec une oxygénation adéquate. Pour atteindre ce but de façon sécuritaire, un monitoring continu in vivo de la pression parrielle artérielle d'oxygène serait préférable à l'analyse intermittente des gaz artériels. Nous rapportons le management fructueux d' ut patient ayant subi une thoracotomie apres l" administration de la bléomycine en utilisant un dispositif de mesure de $\mathrm{PO}_{2}$ intravasculaire pour obtenir la lecture continue de la pression partielle d'oxygène. L'utilisation et les limites $d$ un tel dispositif sont discutées. 